\title{
HOW SMOOTH SHOULD CURVES BE FOR CALIBRATING RADIOCARBON AGES?
}

\author{
TORBJÖRN E. TÖRNQVIST and MARC F. P. BIERKENS
}

\author{
Department of Physical Geography, Utrecht University, P.O. Box 80115, NL-3508 TC Utrecht \\ The Netherlands
}

\begin{abstract}
We show that smoothed versions of the high-resolution calibration curve should be used when ${ }^{14} \mathrm{C}$ ages are calibrated with large $\left(>\sim 30{ }^{14} \mathrm{C} \mathrm{yr}\right)$ measurement errors (represented by standard deviation $\sigma_{\mathrm{m}}$ ) or are mixtures of elements of variable age (natural sample error with standard deviation $\sigma_{n}$ ). The degree of smoothing should agree with the standard deviation of total sample error, $\sigma_{t}$, the square root of the quadratic sum of $\sigma_{m}$ and $\sigma_{n}$. However, in most cases, $\sigma_{t}$ is not well known, especially due to difficulties in quantifying $\sigma_{n}$. We present an inverse method that gives a measure of mean $\sigma_{t}$ for different materials that are widely used in (conventional) ${ }^{14} \mathrm{C}$ dating. Calculations with large $(>100)$ data sets of wood, charcoal, ombrotrophic peat and minerotrophic peat/gyttja samples indicate that $\sigma_{t}$ of such materials is generally much larger than previously assumed, mainly because of large values of $\sigma_{n}$. This means that particularly in organic deposits, strongly smoothed calibration curves should be used where medium-term ${ }^{14} \mathrm{C}$ variations (wiggles) are completely straightened. This has especially major consequences for calibrating ${ }^{14} \mathrm{C}$ histograms for natural ${ }^{14} \mathrm{C}$ variations. We conclude that ${ }^{14} \mathrm{C}$ histograms consisting of samples of organic deposits do not require correction for medium-term ${ }^{14} \mathrm{C}$ variations and that uncalibrated ${ }^{14} \mathrm{C}$ histograms need not be as suspect as is usually believed.
\end{abstract}

\section{INTRODUCTION}

Calibration of ${ }^{14} \mathrm{C}$ ages has rapidly evolved into a standard procedure for ${ }^{14} \mathrm{C}$ users, facilitated by the development of numerous calibration programs (Aitchison et al. 1989). Calibration is usually performed with a high-resolution standard calibration curve, but it is questionable whether the use of such a detailed calibration curve is always justified. The calibration data of Stuiver and Pearson (1986), Pearson and Stuiver (1986) and Pearson et al. (1986), which have been the most widely used, are based on high-precision ${ }^{14} \mathrm{C}$ measurements of tree rings with very small standard deviations. Nearly all regular ${ }^{14} \mathrm{C}$ ages have significantly larger standard deviations, suggesting that, in such cases, the use of a smoothed version of the calibration curve may be more appropriate. A related problem in calibrating ${ }^{14} \mathrm{C}$ ages has been discussed by Mook, de Jong and Geertsema (1979), Mook (1983), Stuiver and Pearson (1986), Pearson and Stuiver (1986) and Michczyńska, Pazdur and Walanus (1990). This refers to the time range into which the sample fits (sample "time width" according to Mook 1983), which is also important for choosing a calibration curve. Because the high-resolution calibration curve is based on samples with small time widths ( $20 \mathrm{cal} \mathrm{yr}$ ), it shows subtle ${ }^{14} \mathrm{C}$ variations that are probably not detectable in samples (e.g., sediment samples) of significantly larger time width. Thus, the original calibration curve should be smoothed to suit the type of sample used before the calibration is carried out (Mook 1983).

We consider ${ }^{14} \mathrm{C}$ samples as populations of elements with different ${ }^{14} \mathrm{C} /{ }^{12} \mathrm{C}$ ratios (Appendix 1 ) containing two error sources: 1 ) natural sample error, $\varepsilon_{\mathrm{n}}$, which is a measure of the degree of mixing of various elements of different age in the sample and is represented by standard deviation $\sigma_{n}$; and 2) measurement error, $\varepsilon_{m}$, which is represented by the standard deviation $\sigma_{m}$, as determined by the laboratory. The former is familiar to the concept of time width as introduced by Mook (1983). Time width refers to the number of calendar years represented by a sample. Only at times (notably with wood) is it possible to establish this accurately. A direct relation exists between time width and $\sigma_{n}$, as discussed in Appendix 2.

Most samples, such as organic deposits and charcoal, have unknown $\sigma_{n}$, which consists partly of the time width of the sample, and partly of various types of contamination. Note that our statistical assumption is that contamination will rarely lead to bimodal probability distributions. We expect 
unimodal and more or less symmetrical probability distributions which can be described appropriately by the standard deviation. It is almost impossible to estimate contamination quantitatively for individual samples, but it may be significantly larger than the error resulting from sample time width alone. The standard deviation of total sample error, $\sigma_{\mathfrak{t}}$, must be established quantitatively to select the appropriate calibration curve for one ${ }^{14} \mathrm{C}$ sample or a set of ${ }^{14} \mathrm{C}$ samples. If $\sigma_{\mathrm{n}}$ is independent of $\sigma_{\mathrm{m}}$ (see Appendix 1), $\sigma_{\mathrm{t}}$ is obtained by (cf. Mook and Streurman 1983)

$$
\sigma_{\mathrm{t}}=\sqrt{\left(\sigma_{\mathrm{n}}^{2}+\sigma_{\mathrm{m}}^{2}\right)} \quad\left[{ }^{14} \mathrm{C} \mathrm{yr}\right] .
$$

Until now, it has been difficult to determine $\sigma_{t}$ because of problems in determining $\sigma_{n}$. Thus, a suitable version of the calibration curve has usually been chosen by simply estimating mean time width of a sample with no quantitative analysis (e.g., Mook 1983; Stolk, Hogervorst and Berendsen 1989). We present here an inverse method that estimates $\sigma_{t}$ (and thus, $\sigma_{n}$, because $\sigma_{m}$ is known) based on large (>100) data sets of various types of samples widely used in (conventional) ${ }^{14} \mathrm{C}$ dating. As will be shown, such an analysis has significant consequences for ${ }^{14} \mathrm{C}$ age calibration. Our results are particularly important for calibrating ${ }^{14} \mathrm{C}$ histograms for ${ }^{14} \mathrm{C}$ variations.

\section{METHODS}

\section{"Real" and "Theoretical" ${ }^{14} \mathrm{C}$ Histograms}

We selected published ${ }^{14} \mathrm{C}$ ages of different types of sample material and constructed ${ }^{14} \mathrm{C}$ histograms for each of these types (Fig. 1), using the CALHIS program (Stolk et al. 1994). ${ }^{14} \mathrm{C}$ histograms are obtained by superimposing individual ${ }^{14} \mathrm{C}$ ages, each represented by a Gaussian distribution. This resulted in a data set for each type of material consisting of intensity I (the height of the ${ }^{14} \mathrm{C}$ histogram) for every 10 th ${ }^{14} \mathrm{C}$ yr. These four data sets are referred to as "real" ${ }^{14} \mathrm{C}$ histograms. Second, we calculated a parameter that represents the degree of clustering of ${ }^{14} \mathrm{C}$ ages due to natural ${ }^{14} \mathrm{C}$ variations that can be expected for samples equally distributed over the calendar time scale. This parameter, the C-value, is calculated for the same segments of $10{ }^{14} \mathrm{C}$ yr as in the "real" ${ }^{14} \mathrm{C}$ histograms, with the equation (see also Fig. 2)

$$
\mathrm{C}=\Delta \mathrm{cal} \text { yr } / \Delta{ }^{14} \mathrm{C} \text { yr } \quad \text { where } \Delta{ }^{14} \mathrm{C} \mathrm{yr}=10 .
$$

We used 25 calibration curves, each with different degrees of smoothing, for this analysis (Fig. 3A). We smoothed the curves using the SMOOTH program, which is part of the Groningen calibration package (van der Plicht and Mook 1989; van der Plicht 1993). This program calculates moving averages over the calendar time scale using a Gauss-function for weighting. Our most detailed calibration curve (calculated with a Gauss-function with smoothing parameter $\sigma_{s}=8$ ) contains all the details of the high-resolution calibration curve, whereas a curve smoothed with $\sigma_{s}=200$ only registers the long-term ${ }^{14} \mathrm{C}$ variations (wiggles have been completely straightened; Fig. 3A).

A plot of C-values vs. ${ }^{14} \mathrm{C}$ age (Fig. 3B) can be regarded as a "theoretical" ${ }^{14} \mathrm{C}$ histogram that is expected when the distribution of ${ }^{14} \mathrm{C}$ samples over the calendar time scale is homogeneous. Peaks and troughs in such a histogram result entirely from ${ }^{14} \mathrm{C}$ variations. Because $\mathrm{C}$-values were calculated for each of the 25 calibration curves, we obtained 25 "theoretical" ${ }^{14} \mathrm{C}$ histograms, each corresponding to a calibration curve with a different $\sigma_{s}$ value. Our method performs a quantitative comparison of the ${ }^{14} \mathrm{C}$ histograms constructed for different data sets ("real" ${ }^{14} \mathrm{C}$ histograms) and this sequence of "theoretical" ${ }^{14} \mathrm{C}$ histograms. The idea behind this comparison is that the "theoretical" ${ }^{14} \mathrm{C}$ histogram that shows the best correspondence with a "real" ${ }^{14} \mathrm{C}$ histogram represents the cali- 
Wood $(\mathrm{N}=105)$

Charcoal $(\mathrm{N}=256)$
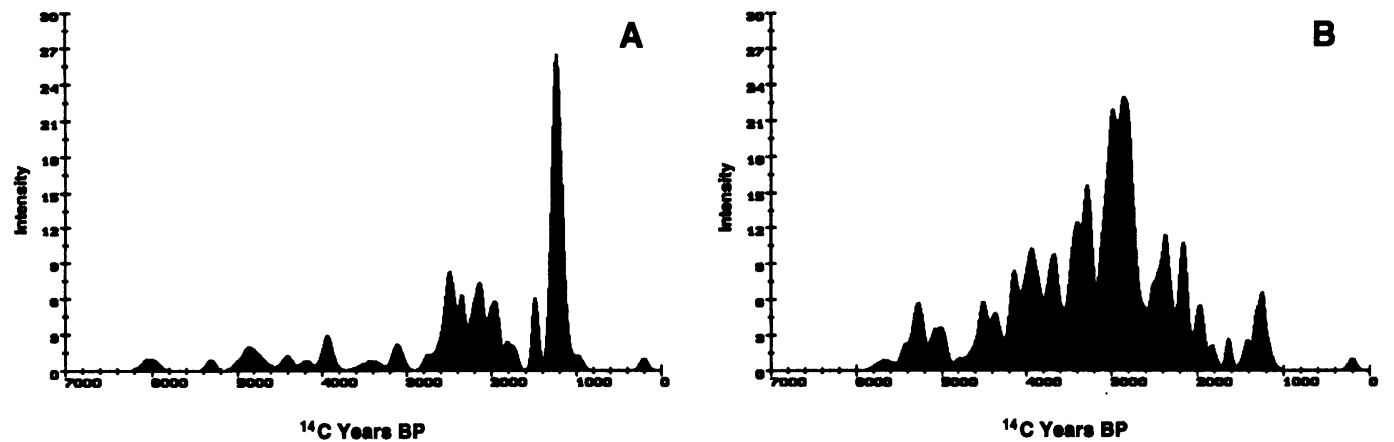

Ombrotrophic peat $(\mathrm{N}=97)$

Minerotrophic peat/gyttja $(N=139)$
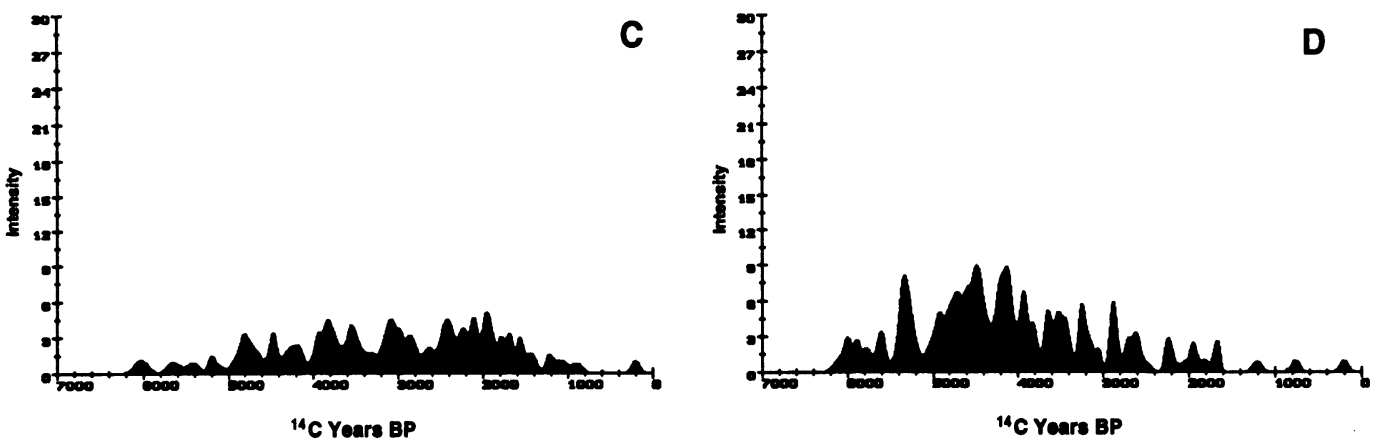

${ }^{14} \mathrm{C}$ Years BP

Fig. $1 .{ }^{14} \mathrm{C}$ histograms of data sets of (A) wood, (B) charcoal, (C) ombrotrophic peat and (D) minerotrophic peat/gyttja, constructed with the CALHIS program (Stolk et al. 1994). Standard peak at $200 \mathrm{yr}$ BP represents one ${ }^{14} \mathrm{C}$ age with $\mathrm{I}=1$ and $\sigma_{\mathrm{m}}$ $=45$. The raw data were obtained from various sources; wood and charcoal: Lanting and Mook (1977); ombrotrophic peat: Janssen and ten Hove (1971), Casparie (1972), van Geel (1972, 1978), Middeldorp (1982, 1986), Dupont and Brenninkmeijer (1984), Kuhry (1985), Witte and van Geel (1985), Dupont (1986); minerotrophic peat/gyttja: Berendsen (1982), van der Woude (1983), van Dijk, Berendsen and Roeleveld (1991), Törnqvist and van Dijk (1993).

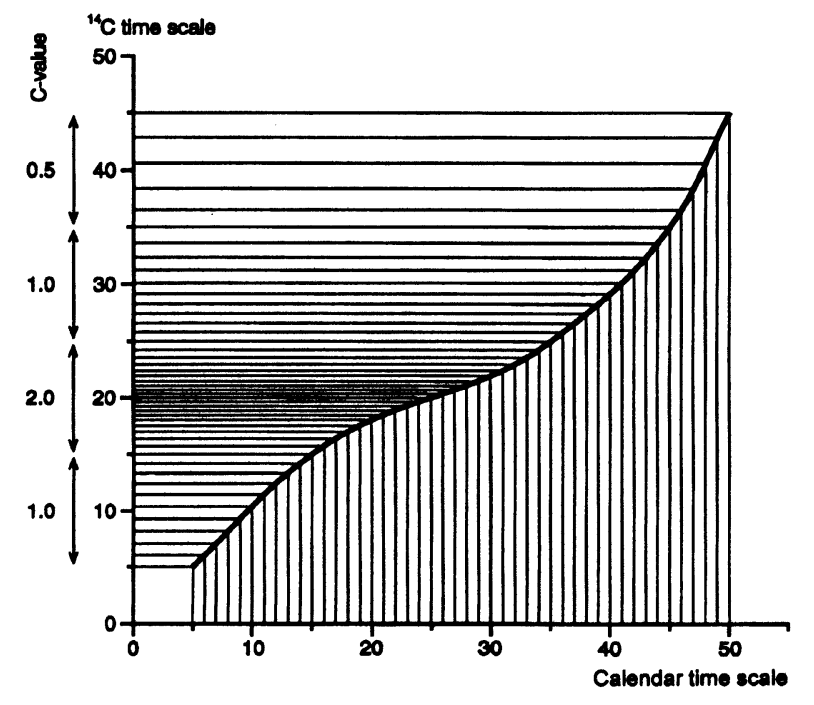

Fig. 2. Determination of the C-value. a theoretical calibration curve; $=$ fictitious ${ }^{14} \mathrm{C}$ ages for each calendar year unequally distributed over the ${ }^{14} \mathrm{C}$ time scale due to ${ }^{14} \mathrm{C}$ variations. The $\mathrm{C}$-value is determined for every 10 th ${ }^{14} \mathrm{C}$ yr. 
bration curve that should be used for the type of sample from which the "real" ${ }^{14} \mathrm{C}$ histogram is constructed.

\section{Determining Correspondence between "Real" and "Theoretical" ${ }^{14} \mathrm{C}$ Histograms}

Because the range of C-values is different for each calibration curve (Fig. 3B), we subdivided the Cvalues into eight classes of equal size (C-class 1 being the smallest $12.5 \%$ of the $\mathrm{C}$-values, $\mathrm{C}$-class 8 the largest; Figs. $3 \mathrm{C}-\mathrm{E})$. First we determined the intensity of each C-class in the "real" ${ }^{14} \mathrm{C}$ histogram, which revealed the observed intensity for each C-class ( $I_{i}^{\text {obs; }}$; see Appendix 3$)$. If there is no

A

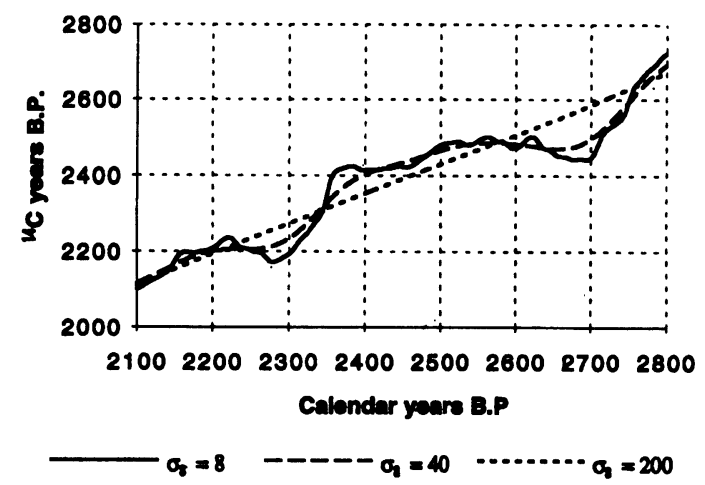

C

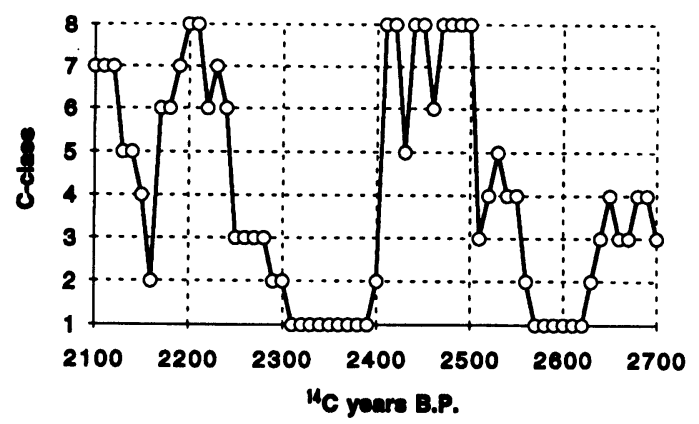

E

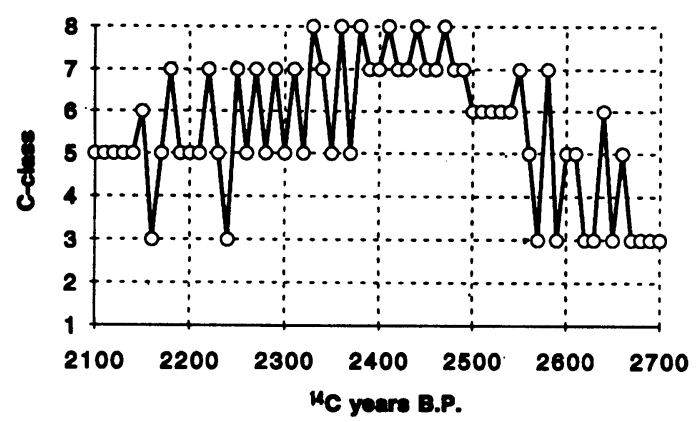

$\mathbf{B}$
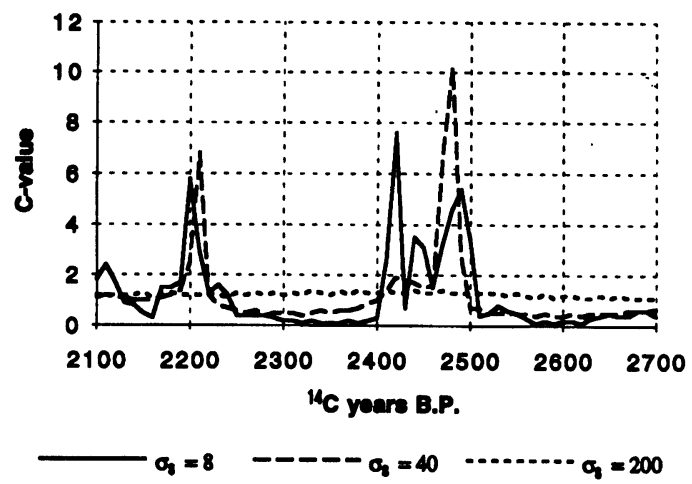

D $\quad \sigma_{3}=\mathbf{4 0}$

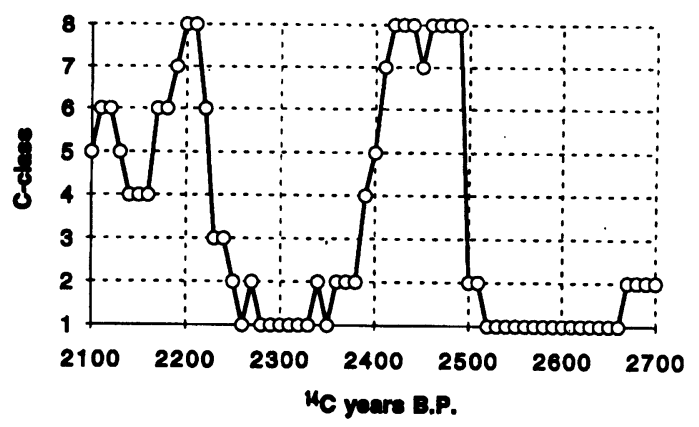

Fig. 3. Examples of (A) calibration curves with different smoothing parameters, $\sigma_{s}$ (B) C-values calculated for these curves for the ${ }^{14} \mathrm{C}$ age range, 2100 to 2700 yr BP, and (C-E) C-classes determined for these curves for the same time interval 
relation between the "real" ${ }^{14} \mathrm{C}$ histogram and the "theoretical" ${ }^{14} \mathrm{C}$ histogram, we expect an equal intensity for each C-class. This is the intensity that can be expected in each C-class in the case of random distribution of ${ }^{14} \mathrm{C}$ ages $\left(\mathrm{I}_{\mathrm{i}}^{\exp }\right)$, without any clustering due to ${ }^{14} \mathrm{C}$ variations. In principle, $\mathrm{I}_{\mathrm{i}}^{\text {exp }}$ can be calculated easily for each $\mathrm{C}$-class by dividing the total intensity by the number of $\mathrm{C}$ classes. However, the unequal large-scale distribution of ${ }^{14} \mathrm{C}$ ages over the ${ }^{14} \mathrm{C}$ time scale in most of our data sets (Fig. 1), combined with the irregular distribution of the C-class numbers over the ${ }^{14} \mathrm{C}$ time scale, require a weighted calculation, as discussed in Appendix 3.

If ${ }^{14} \mathrm{C}$ ages cluster in certain time intervals due to ${ }^{14} \mathrm{C}$ variations, indicating a relation between the "real" and the "theoretical" ${ }^{14} \mathrm{C}$ histogram, the ratio $\mathrm{I}_{\mathrm{i}}^{\text {obs }} / \mathrm{I}_{\mathrm{i}}^{\exp }$ will be $<1$ for the lower C-classes and $>1$ for the higher C-classes. If the $\mathrm{I}_{\mathrm{i}}^{\text {obs }} / \mathrm{I}_{\mathrm{i}}^{\text {exp }}$ ratio is plotted $v s$. C-class number, the slope, a, of a regression line through the data points is a measure of the degree of correspondence between the "real" and the "theoretical" ${ }^{14} \mathrm{C}$ histograms for the calibration curve used (Fig. 4).
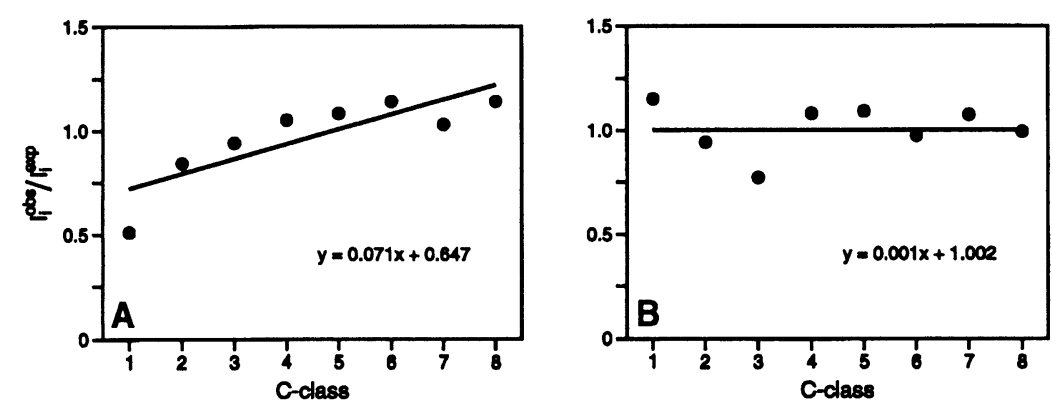

Fig. 4. Scatterplot of the $I_{i}^{\text {obs }} / I_{i}^{\text {exp }}$ ratio vs. C-class number and a linear regression line through the data points. Examples are given of the result for charcoal with (A) a calibration curve with $\sigma_{3}=96$ and (B) a calibration curve with $\sigma_{3}=200$. The former shows a significant relation between $\mathrm{I}_{\mathrm{i}}^{\text {obs }} / \mathrm{I}_{\mathrm{i}}^{\text {exp }}$ ratio and C-class, the latter not.

\section{Estimating $\sigma_{\mathfrak{t}}$}

When samples with large values of $\sigma_{t}$ are calibrated with a calibration curve that is too detailed, the resulting probability distributions will contain artifacts. On the other hand, a curve that is too smooth will not correct sufficiently for ${ }^{14} \mathrm{C}$ variations, which actually may be detectable in ${ }^{14} \mathrm{C}$ samples. Thus, the "theoretical" ${ }^{14} \mathrm{C}$ histogram that corresponds the best to the "real" ${ }^{14} \mathrm{C}$ histogram represents the most suitable calibration curve for that specific type of sample; it will correct for all relevant variation without producing artifacts. The $\sigma_{s}$ value with the maximum slope of the $I_{i}^{\text {obs } / ~}$ $\mathrm{I}_{\mathrm{i}}^{\text {exp }}$ ratio is a measure for $\sigma_{t}$ and vice versa. The relation between $\sigma_{t}$ and $\sigma_{s}$ is complex because $\sigma_{s}$ is expressed in calendar years and $\sigma_{t}$ in ${ }^{14} \mathrm{C}$ years. However, a conversion method is presented in Appendix 4, which can be used for estimating $\sigma_{t}$ from $\sigma_{s}$ for larger data sets. By plotting the slope, a, of the $\mathrm{I}_{\mathrm{i}}^{\text {obs }} / \mathrm{I}_{\mathrm{i}}^{\text {exp }}$ ratio regression line $v s$. the smoothing parameter, $\sigma_{\mathrm{s}}$, of the calibration curves, we estimate $\sigma_{t}$ by means of an inverse method.

\section{RESULTS}

\section{Experiments}

We applied the procedure described above first to test the method. We used the set of ${ }^{14} \mathrm{C}$ ages that formed the basis for the standard calibration curve (Stuiver and Pearson 1986; Pearson and Stuiver 1986; Pearson et al. 1986) and calculated a $\sigma_{\mathrm{s}}$-a plot for their high-precision wood samples. The 
result (Fig. 5) is as expected: a steadily decreasing slope of the $I_{i}^{\text {obs }} /{ }_{i}^{\text {exp }}$ ratio with increased smoothing of the calibration curve. The maximum value is found at the most detailed calibration curve ( $\sigma_{\mathrm{s}}$ $=8$ ). Obviously, this is because mean $\sigma_{\mathrm{m}}$ is only $12.7{ }^{14} \mathrm{C} \mathrm{yr}$ (Table 1 ) and $\sigma_{\mathrm{n}}$ is also very small, since the time width covered by the samples is only $20 \mathrm{cal} \mathrm{yr}$.

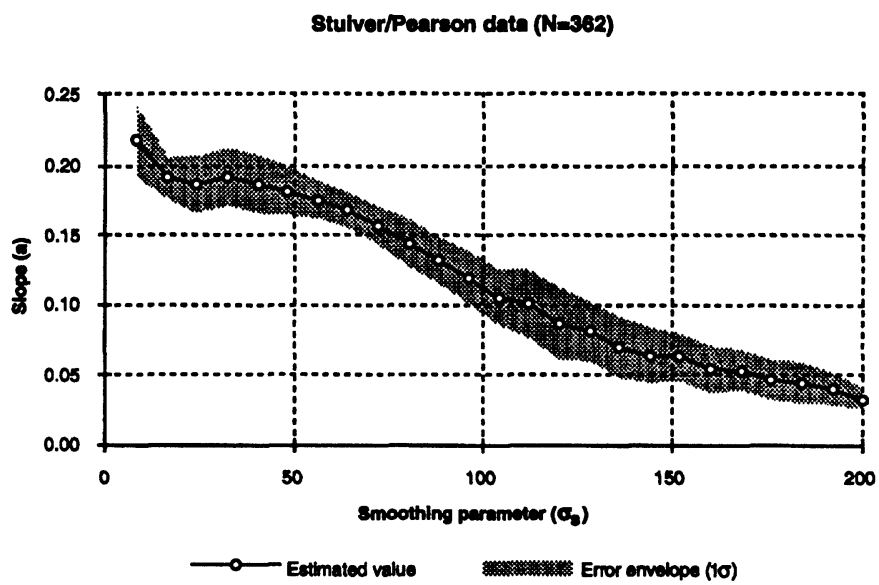

Fig. 5. $\sigma_{\mathrm{s}}$-a plot of the Stuiver and Pearson (1986), Pearson and Stuiver (1986) and Pearson et al. (1986) data set

TABLE 1. Mean Measurement Error, $\sigma_{m}$, of Different Data Sets Used in This Study

\begin{tabular}{lrc}
\hline Data set & $\mathrm{N}$ & $\begin{array}{c}\text { Mean } \sigma_{\mathrm{m}} \\
\left({ }^{14} \mathrm{C} \mathrm{yr}\right)\end{array}$ \\
\hline Stuiver/Pearson data & 362 & $12.7 \pm 3.7$ \\
Wood & 105 & $46.2 \pm 21.1$ \\
Charcoal & 256 & $46.8 \pm 16.8$ \\
Ombrotrophic peat & 97 & $56.4 \pm 19.1$ \\
Minerotrophic peat/gyttja & 139 & $59.3 \pm 19.4$ \\
Charcoal (high $\left.\sigma_{\mathrm{m}}\right)$ & 100 & $62.9 \pm 16.1$ \\
Charcoal (low $\left.\sigma_{\mathrm{m}}\right)$ & 100 & $33.8 \pm 2.5$ \\
\hline
\end{tabular}

Before analyzing and comparing data sets of different materials, we also investigated the number of ${ }^{14} \mathrm{C}$ ages required to arrive at reproducible results. We used charcoal samples $(\mathrm{N}=256)$ and selected 3 random sets of 50 and 3 of $100{ }^{14} \mathrm{C}$ ages. In neither random set did mean $\sigma_{\mathrm{m}}$ differ significantly from mean $\sigma_{\mathrm{m}}$ of the total data set. A comparison of $\sigma_{\mathrm{s}}$-a plots of the total charcoal data set with the 50 (Fig. 6A) and 100 ages (Fig. 6B) showed that data sets of 50 were too small, indicated by the large differences among the curves of Figure 6A. Not only did their absolute values differ, but their shapes especially differed (maximum values of a are reached at different values of $\sigma_{\mathrm{s}}$ ). Figure 6B shows that sets of 100 yield much better results; the shape of the three curves strongly resembles the "total charcoal" curve. This suggests that data sets of $>100$ are needed to obtain useful $\sigma_{\mathrm{s}}$-a plots.

We also analyzed the effect of different $\sigma_{\mathrm{m}}$ values. Again, we used our charcoal data set, and split it into two subsets of 100 samples each; one with low standard deviations and one with high standard deviations (Table 1). A comparison of the two, together with the "total charcoal" curve (Fig. 7) confirms that $\sigma_{m}$ strongly influences $\sigma_{t}$. Maximum values for charcoal samples with low $\sigma_{m}$ are found 
Effect of emaller data sots $(\mathrm{N}-50)$

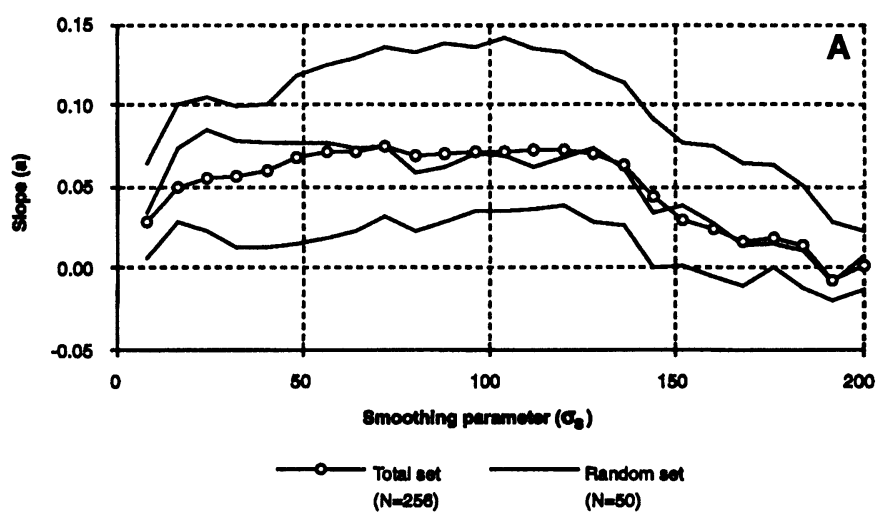

Effect of smaller data sots $(\mathrm{N}=100)$

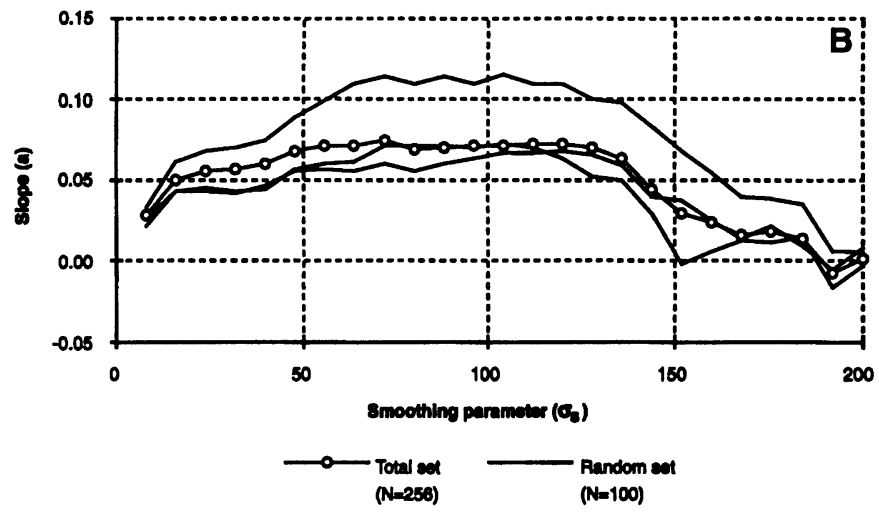

Fig. 6. $\sigma_{3}$-a plots of various data sets of charcoal. Comparison of data sets of (A) 50 samples each and (B) 100 samples each with the total charcoal data set

at smoothing parameters of $c a .60$; for samples with high $\sigma_{m}$, maximum values are found at $c a .120$. This confirms that smoothed curves are needed when samples with high standard deviations are calibrated.

\section{Analysis of Different Materials}

\section{Data Selection}

We critically selected ${ }^{14} \mathrm{C}$ ages of four types of material widely used in ${ }^{14} \mathrm{C}$ dating: wood, charcoal, ombrotrophic peat and minerotrophic peat/gyttja. We used ${ }^{14} \mathrm{C}$ results from only one laboratory (Groningen), to rule out possible interlaboratory differences (International Study Group 1982; Scott et al. 1990). Further, we only selected samples with numbers higher than GrN-4046, because these were corrected for isotope fractionation (Lanting and Mook 1977). We restricted our sample selection to the time interval, 110-6100 BP, the period covered by the calibration data of Stuiver and Pearson (1986), Pearson and Stuiver (1986) and Pearson et al. (1986). 


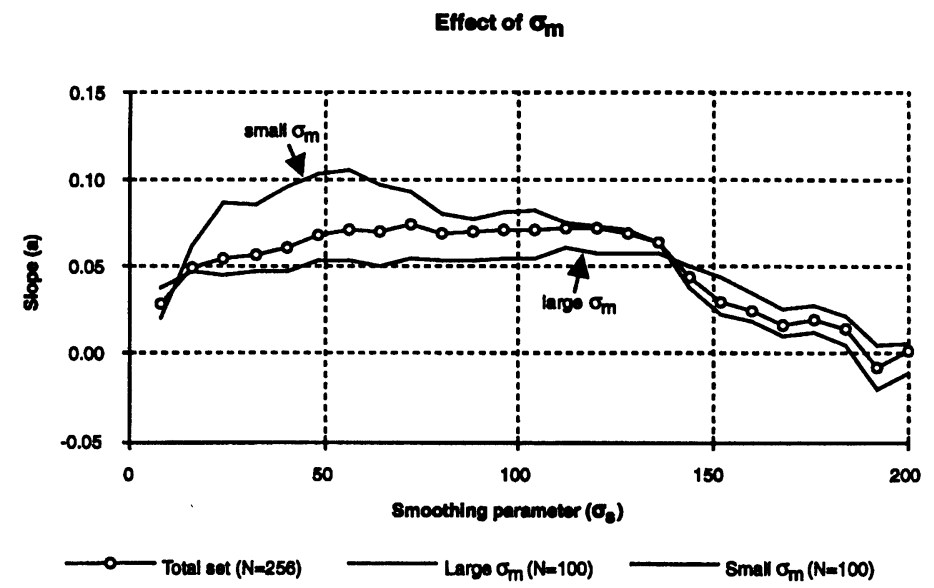

Fig. 7. $\sigma_{3}$-a plots of various data sets of charcoal. Comparison of a data set with low $\sigma_{m}$ and high $\sigma_{m}$ with the total charcoal data set

Wood and charcoal samples were archaeological samples from The Netherlands. The ombrotrophic peat samples were obtained from raised bogs, mainly in the eastern Netherlands. The minerotrophic peat/gyttja samples, which usually have a significant admixture of clay, are all from the RhineMeuse delta (central Netherlands). To obtain a homogeneous data set, we used only minerotrophic peat/gyttja samples that had not been manually pretreated (e.g., by systematic removal of roots). Figure 1 shows ${ }^{14} \mathrm{C}$ histograms of the 4 data sets.

\section{Results and Interpretation}

Figure 8 shows the results of all our analyses. The $\sigma_{\mathrm{s}}$-a plots of wood (Fig. 8A) and charcoal (Fig. 8B) show significant maximum values of the slope of the $\mathrm{I}_{\mathrm{i}}^{\text {obs }} / \mathrm{I}_{\mathrm{i}}^{\text {exp }}$ ratio. This is not the case in the $\sigma_{\mathrm{s}}$-a plots of the organic deposits (Fig. $8 \mathrm{C}, \mathrm{D}$ ), where a horizontal line can be drawn through the error envelopes. The maximum values in Figures $8 \mathrm{~A}$ and $8 \mathrm{~B}$ do not occur as distinct peaks, as they do in the Stuiver/Pearson data of Figure 5, but as plateaus. This is not surprising; the variability of $\sigma_{\mathrm{m}}$ for these data sets is much higher than for the Stuiver/Pearson data (Table 1). The range of maximum values is especially wide in the charcoal curve $\left(\sigma_{s}=48-136\right.$, mean 92$)$. Thus, we conclude that the variability of $\sigma_{n}$ in the charcoal samples contributes much to this phenomenon. Mean $\sigma_{n}$ can be calculated easily with the equation

$$
\sigma_{\mathrm{n}}=\sqrt{\left(\sigma_{\mathrm{t}}^{2}-\sigma_{\mathrm{m}}^{2}\right)} \quad\left[{ }^{14} \mathrm{C} \mathrm{yr}\right] .
$$

Determining $\sigma_{\mathrm{n}}$ from $\sigma_{\mathrm{s}}$-a plots requires that $\sigma_{\mathrm{t}}\left({ }^{14} \mathrm{C} \mathrm{yr}\right)$ is estimated from $\sigma_{\mathrm{s}}(\mathrm{cal} \mathrm{yr})$. Using the method discussed in Appendix 4, the correction factor for the conversion of $\sigma_{s}$ into $\sigma_{t}(1 / Q)$ was calculated for the ranges 2800-1000 BP (wood) and 4600-1800 BP (charcoal), the time intervals that contained most of the ${ }^{14} \mathrm{C}$ ages of these materials (Fig. 1). Using Equation 3, mean $\sigma_{\mathrm{n}}$ for charcoal can be estimated at $\mathrm{ca}$. 50, whereas for wood (range of maximum values at $\sigma_{s}=24-72$, mean 48), the value is close to 0 . Note that this calculation is only valid if the laboratory error multiplier (Stuiver and Pearson 1986; Pearson and Stuiver 1986) is close to 1.0. If the laboratory error multiplier is large, the contribution of $\sigma_{n}$ to $\sigma_{t}$ is overestimated.

The situation is rather different for the data sets of ombrotrophic peat and minerotrophic peat/gyttja. The $\sigma_{s}$-a plots (Fig. 8C, D) not only show much lower values of a, they are also more or less flat. 

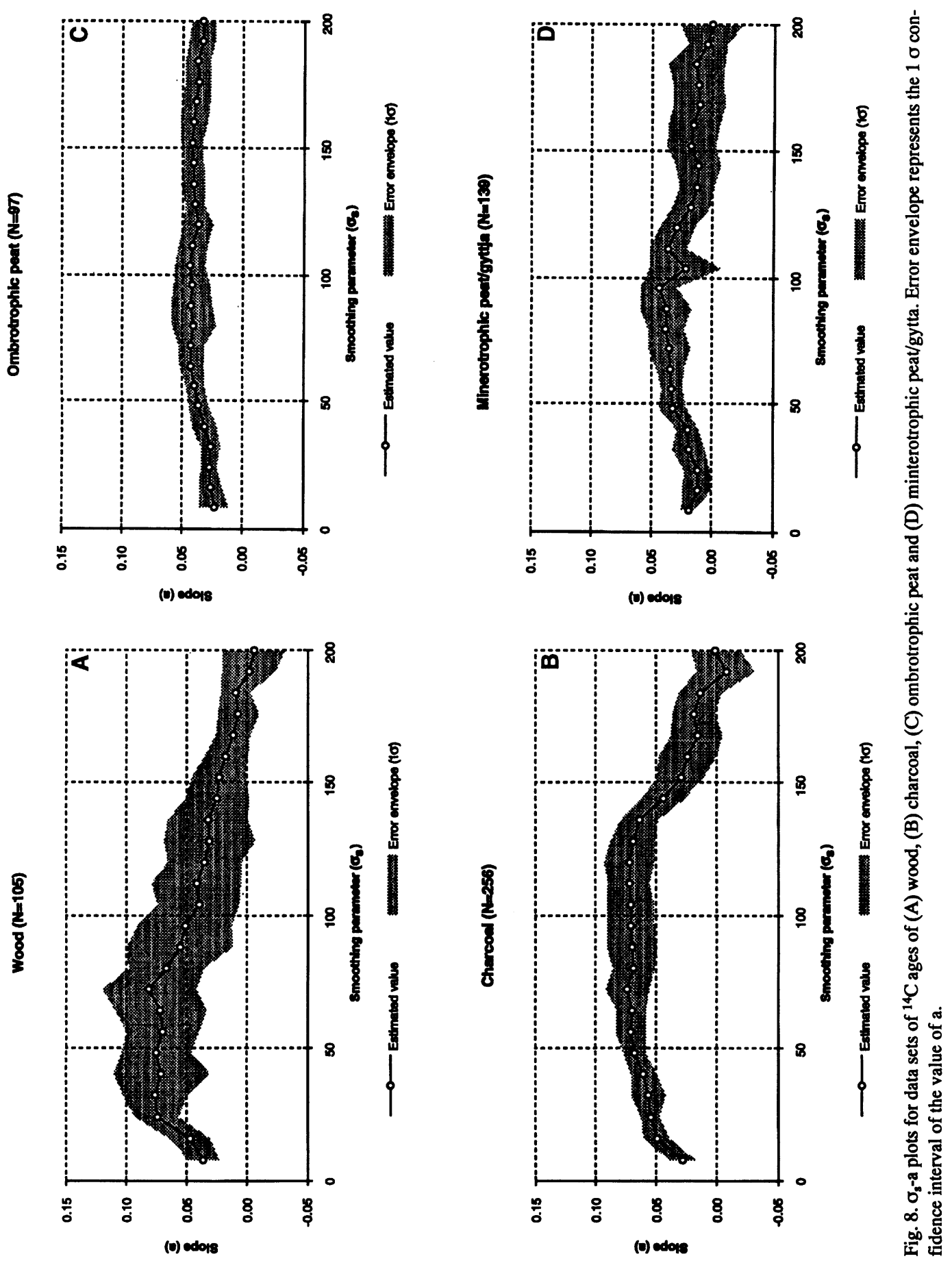
Weak maxima seem to occur at values of $\sigma_{s}$ of $60-100$, but virtually all results are within each other's error limits, and thus not statistically significant. The conclusion is that medium-term ${ }^{14} \mathrm{C}$ variations cannot be detected in large data sets of bulk ${ }^{14} \mathrm{C}$ samples of these materials.

\section{DISCUSSION AND RECOMMENDATIONS}

\section{General Implications for Calibration}

Our experimental results show that $\sigma_{\mathrm{n}}$ (the standard deviation of natural sample error) and $\sigma_{\mathrm{m}}$ (the standard deviation of measurement error) strongly influence the degree at which medium-term ${ }^{14} \mathrm{C}$ variations are detectable in ${ }^{14} \mathrm{C}$ samples. As mentioned above, curves for calibrating ${ }^{14} \mathrm{C}$ ages need to agree with the standard deviation of total sample error $\left(\sigma_{t}\right)$, in order to arrive at correct calibration results. The degree of smoothing of calibration curves depends on the type of material. Until now, appropriate calibration curves have been chosen on the basis of a "best guess" approach; for example, for sediment samples, 100-cal-yr moving averages of the high-resolution curve have been proposed (Mook 1983; Stuiver and Pearson 1986; Pearson and Stuiver 1986; Stolk, Hogervorst and Berendsen 1989). Our results show that a 100-cal-yr moving average smoothed version of the highresolution calibration curve (comparable to our $\sigma_{\mathrm{s}}=40$ curve) will usually be too low an estimate. Especially organic deposits require a much smoother curve, which only reflects long-term ${ }^{14} \mathrm{C}$ variations.

The results obtained for organic deposits are not very surprising in view of recent findings that contamination of bulk minerotrophic peat/gyttja samples may produce age deviations on the order of several centuries (Törnqvist et al. 1992). The results for wood and charcoal also agree with expectations. The low $\sigma_{\mathrm{n}}$ determined for wood samples confirms the general opinion that wood yields excellent ${ }^{14} \mathrm{C}$ ages because of its well-defined and usually narrow time width, and because it is unlikely to be contaminated. More problems occur with charcoal samples, which are more likely to contain contaminants. Further, $\sigma_{n}$ of charcoal is very variable, according to our results.

In $\sigma_{\mathrm{s}}$-a plots with maximum values as plateaus, for example, in our charcoal data set (Fig. 8B), the choice of a suitable calibration curve is ambiguous. If one uses a calibration curve that is too smooth, probability distributions are not sufficiently corrected for the influence of medium-term ${ }^{14} \mathrm{C}$ variations. On the other hand, a curve that is too detailed will reveal irregular probability distributions consisting of narrow and high peaks, which are, in fact, artifacts. Both situations should be avoided. To eliminate ambiguity, we recommend using the mean value of $\sigma_{s}$ in the plateau. We realize that this is a subjective choice, but the use of the mean value is most likely the best way to reduce potential error as much as possible. For our charcoal data set, $\sigma_{\mathrm{s}}=100$ is appropriate; for our wood samples, the value should be 50 . For our peat samples, any calibration curve reflecting medium-term ${ }^{14} \mathrm{C}$ variations is too detailed; here, the completely smooth $\sigma_{\mathrm{s}}=200$ curve is suitable for avoiding artifacts. In general, for the proper calibration of ${ }^{14} \mathrm{C}$ ages, calibration programs need to have a smoothing option and the smoothing method needs to be described clearly.

When one calibrates results of other types of material where large data sets are not available, the method presented here cannot be used. If sample time width (expressed in cal yr) is accurately known or can be estimated reasonably well, it may be necessary to calculate $\sigma_{\mathrm{n}}$ (expressed in ${ }^{14} \mathrm{C} \mathrm{yr}$ ) from the time width value, to arrive at an acceptable estimate of $\sigma_{t}$. A calculation method is presented in Appendix 2.

The inverse method used here yields only average results for large data sets, which, as has been shown, usually are very variable. Thus, the first step should be an evaluation of all relevant evi- 
dence available for individual samples, before considering the use of the results of this inevitably imprecise method.

\section{Implications for Calibration of ${ }^{14} \mathrm{C}$ Histograms}

When individual ${ }^{14} \mathrm{C}$ ages are calibrated, interest is usually focused on the calendar age range rather than the shape of the probability distribution. In such cases, the calibration result is usually not very sensitive to the degree of smoothing of the calibration curve. However, if the probability distribution of the calibrated ${ }^{14} \mathrm{C}$ age is important, the selection of a calibration curve becomes critical. The use of high-resolution calibration curves results in irregular calendar age probability distributions, whereas strongly smoothed calibration curves will result in probability distributions that remain generally Gaussian. This has important consequences for the calibration of ${ }^{14} \mathrm{C}$ histograms for ${ }^{14} \mathrm{C}$ variations. When calibrated ${ }^{14} \mathrm{C}$ histograms consist of summed probability distributions of individually calibrated ${ }^{14} \mathrm{C}$ ages (Stuiver and Reimer 1989; Stolk et al. 1994) the choice of the calibration curve is most crucial.

It has long been recognized that care should be taken with interpreting ${ }^{14} \mathrm{C}$ histograms that have not been corrected for ${ }^{14} \mathrm{C}$ variations (e.g., Geyh 1971; de Jong and Mook 1981), resulting in a general suspicion of uncalibrated ${ }^{14} \mathrm{C}$ histograms. Peaks and troughs in uncalibrated ${ }^{14} \mathrm{C}$ histograms were thought to be the result of medium-term ${ }^{14} \mathrm{C}$ variations rather than the phenomena of interest. Our results show that calibration of ${ }^{14} \mathrm{C}$ histograms for medium-term ${ }^{14} \mathrm{C}$ variations may not be necessary, depending on the type of material. In the case of organic deposits, which have been widely used for constructing ${ }^{14} \mathrm{C}$ histograms, disturbing effects of medium-term ${ }^{14} \mathrm{C}$ variations are unlikely, and uncalibrated ${ }^{14} \mathrm{C}$ histograms are, in principle, very useful. On the other hand, it must be kept in mind that ${ }^{14} \mathrm{C}$ histograms based on bulk organic sediment samples are likely to register contaminating effects (cf. Törnqvist et al. 1992), and thus may have limited value.

Earlier attempts to correct ${ }^{14} \mathrm{C}$ histograms for ${ }^{14} \mathrm{C}$ variations (Geyh 1971,1980 ) revealed synchroneity of peaks in the calibrated histograms with distortions of the ${ }^{14} \mathrm{C}$ time scale. Geyh (1971) assumed a causal relation between medium-term ${ }^{14} \mathrm{C}$ variations (caused by fluctuations in solar activity) and global sea-level changes, although he was later less certain about this relation (Geyh 1980). Our results indicate that peaks in Geyh's calibrated ${ }^{14} \mathrm{C}$ histograms may well be artifacts, resulting from the use of too-detailed calibration curves. Similarly, the large peaks produced by the KORHIS program for calibration of ${ }^{14} \mathrm{C}$ histograms (Stolk, Hogervorst and Berendsen 1989) are also artifacts, as shown by Stolk et al. (1994). Thus, we believe that studies on the relation between medium-term ${ }^{14} \mathrm{C}$ variations and geologic or paleoecologic phenomena should be carried out by wiggle matching ( $c f$. van Geel and Mook 1989).

\section{ACKNOWLEDGMENTS}

We are grateful to Jaap Kwadijk for trouble-shooting during the spreadsheet calculations, and Henk Berendsen, Arie de Jong, Ad Stolk and Hans van der Plicht for critically reading earlier versions of the manuscript.

\section{REFERENCES}

Aitchison, T. C., Leese, M., Michczynska, D. J., Mook, W. G., Otlet, R. L., Ottaway, B. S., Pazdur, M. F., van der Plicht, J., Reimer, P. J., Robinson, S. W., Scott, E. M., Stuiver, M. and Weninger, B. 1989 A comparison of methods used for the calibration of radiocarbon dates. In Long, A., Kra, R. S. and Srdoc, D., eds., Proceedings of the 13th International ${ }^{14} \mathrm{C}$ Conference. $\mathrm{Ra}$ diocarbon 31(3): 846-862.

Berendsen, H. J. A. 1982 De genese van het landschap in het zuiden van de provincie Utrecht, een fysisch-geo- 
grafische studie. Utrechtse Geografische Studies 25: 1-255.

Casparie, W. A. 1972 Bog Development in Southeastern Drenthe (The Netherlands). The Hague, W. Junk: 271 p.

de Jong, A. F. M. and Mook, W. G. 1981 Natural C-14 variations and consequences for sea-level fluctuations and frequency analysis of periods of peat growth. In van Loon, A. J., ed., Quaternary Geology: A Farewell to A. J. Wiggers. Geologie en Mijnbouw 60: 331-336.

Dupont, L. M. 1986 Temperature and rainfall variation in the Holocene based on comparative palaeoecology and isotope geology of a hummock and a hollow (Bourtangerveen, The Netherlands). Review of Palaeobotany and Palynology 48: 71-159.

Dupont, L. M. and Brenninkmeijer, C. A. M. 1984 Palaeobotanic and isotopic analysis of late Subboreal and early Subatlantic peat from Engbertsdijksveen VII, The Netherlands. Review of Palaeobotany and Palynology 41: 241-271.

Geyh, M. A. 1971 Middle and young Holocene sea-level changes as global contemporary events. Geologiska Föreningens $i$ Stockholm Förhandlingar 93: 679-692. 1980 Holocene sea-level history: Case study of the statistical evaluation of ${ }^{14} \mathrm{C}$ dates. In Stuiver, M. and Kra, R. S., eds., Proceedings of the 10 th International ${ }^{14} \mathrm{C}$ Conference. Radiocarbon 22(3): 695-704.

International Study Group 1982 An inter-laboratory comparison of radiocarbon measurements in tree rings. $\mathrm{Na}$ ture 298: 619-623.

Janssen, C. R. and ten Hove, H. A. 1971 Some Late Holocene pollen diagrams from the Peel raised bogs (southern Netherlands). Review of Palaeobotany and $\mathrm{Pa}$ lynology 11: 7-53.

Kuhry, P. 1985 Transgression of a raised bog across a coversand ridge originally covered with an oak-lime forest. Palaeoecological study of a Middle Holocene local vegetational succession in the Amtsven (northwest Germany). Review of Palaeobotany and Palynology 44: 303-353.

Lanting, J. N. and Mook, W. G. 1977 The Pre- and Protohistory of the Netherlands in Terms of Radiocarbon Dates. Groningen: $247 \mathrm{p}$.

Michczyríska, D. J., Pazdur, M. F. and Walanus, A. 1990 Bayesian approach to probabilistic calibration of radiocarbon ages. In Mook, W. G. and Waterbolk, H. T., eds., Proceedings of the 2nd International Symposium ${ }^{14} \mathrm{C}$ and Archaeology. Strasbourg, PACT 29: 69-79.

Middeldorp, A. A. 1982 Pollen concentration as a basis for indirect dating and quantifying net organic and fungal production in a peat bog ecosystem. Review of Palaeobotany and Palynology 37: 225-282.

1986 Functional palaeoecology of the Hahnenmoor raised bog ecosystem - A study of vegetation history, production and decomposition by means of pollen density dating. Review of Palaeobotany and Palynology 49: 1-73.
Mook, W. G. $1983{ }^{14} \mathrm{C}$ calibration curves depending on sample time-width. In Mook, W. G. and Waterbolk, H. T., eds., Proceedings of the International Symposium ${ }^{14} \mathrm{C}$ and Archaeology. Strasbourg, PACT 8: 517-525.

Mook, W. G., de Jong, A. F. M. and Geertsema, H. 1979 Archaeological implications of natural carbon-14 variations. Palaeohistoria 21: 9-18

Mook, W. G. and Streurman, H. J. 1983 Physical and chemical aspects of radiocarbon dating. In Mook, W. G. and Waterbolk, H. T., eds., Proceedings of the International Symposium ${ }^{14} \mathrm{C}$ and Archaeology. Strasbourg, PACT 8: 31-55.

Pearson, G. W., Pilcher, J. R., Baillie, M. G. L., Corbett, D. M. and Qua, F. 1986 High-precision ${ }^{14} \mathrm{C}$ measurement of Irish oaks to show the natural ${ }^{14} \mathrm{C}$ variations from AD 1840 to 5210 BC. In Stuiver, M. and Kra, R. S., eds., Proceedings of the 12 th International ${ }^{14} \mathrm{C}$ Conference. Radiocarbon 28(2B): 911-934.

Pearson, G. W. and Stuiver, M. 1986 High-precision calibration of the radiocarbon time scale, $500-2500 \mathrm{BC}$. In Stuiver, M. and Kra, R. S., eds., Proceedings of the 12th International ${ }^{14} \mathrm{C}$ Conference. Radiocarbon 28(2B): 839-862.

Scott, E. M., Aitchison, T. C., Harkness, D. D., Cook, G. T. and Baxter, M. S. 1990 An overview of all three stages of the International Radiocarbon Intercomparison. In Scott, E. M., Long, A. and Kra, R. S., eds., Proceedings of the International Workshop on Intercomparison of ${ }^{14} \mathrm{C}$ Laboratories. Radiocarbon 32(3): 309319.

Stolk, A., Hogervorst, K. and Berendsen, H. 1989 Correcting ${ }^{14} \mathrm{C}$ histograms for the non-linearity of the radiocarbon time scale. Radiocarbon 31(2): 169-177.

Stolk, A., Törnqvist, T. E., Hekhuis, K. P. V., Berendsen, H. J. A. and van der Plicht, J. 1994 Calibration of ${ }^{14} \mathrm{C}$ histograms: A comparison of methods. Radiocarbon 36(1): 1-10.

Stuiver, M. and Pearson, G. W. 1986 High-precision calibration of the radiocarbon time scale, AD 1950-500 BC. In Stuiver, M. and Kra, R. S., eds., Proceedings of the 12th International ${ }^{14} \mathrm{C}$ Conference. Radiocarbon 28(2B): 805-838.

Stuiver, M. and Reimer, P. 1989 Histograms obtained from computerized radiocarbon age calibration. In Long, A., Kra, R. S. and Srdoc, D., eds., Proceedings of the 13 th International ${ }^{14} \mathrm{C}$ Conference. Radiocarbon 31(3): 817-823.

Törnqvist, T. E. and van Dijk, G. J. 1993 Optimizing sampling strategy for radiocarbon dating of Holocene fluvial systems in a vertically aggrading setting. Boreas 22: 129-145.

Törnqvist, T. E., de Jong, A. F. M., Oosterbaan, W. A. and van der Borg, K. 1992 Accurate dating of organic deposits by AMS ${ }^{14} \mathrm{C}$ measurement of macrofossils. In Long, A. and Kra, R. S., eds., Proceedings of the 14th International ${ }^{14} \mathrm{C}$ Conference. Radiocarbon $34(3)$ : 566-577. 
van der Plicht, J. 1993 The Groningen radiocarbon calibration program. In Stuiver, M., Long, A. and Kra, R. S., eds., Calibration 1993. Radiocarbon 35(1): 231237.

van der Plicht, J. and Mook, W. G. 1989 Calibration of radiocarbon ages by computer. In Long, A., Kra, R. S. and Srdoc, D., eds., Proceedings of the 13th International ${ }^{14} \mathrm{C}$ Conference. Radiocarbon 31(3): 805-816.

van der Woude, J. D. 1983 Holocene paleoenvironmental evolution of a perimarine fluviatile area. Geology and paleobotany of the area surrounding the archeological excavation at the Hazendonk river dune (Western Netherlands). Analecta Praehistorica Leidensia 16: 1-124.

van Dijk, G. J., Berendsen, H. J. A. and Roeleveld, W. 1991 Holocene water level development in The Netherlands' river area; implications for sea-level reconstruction. Geologie en Mijnbouw 70: 311-326.

van Geel, B. 1972 Palynology of a section from the raised peat bog "Wietmarscher Moor", with special reference to fungal remains. Acta Botanica Neerlandica 21: 261-284.

1978 A palaeoecological study of Holocene peat bog sections in Germany and The Netherlands, based on the analysis of pollen, spores and macro- and microscopic remains of fungi, algae, cormophytes and animals. Review of Palaeobotany and Palynology 25: 1-120.

van Geel, B. and Mook, W. G. 1989 High-resolution ${ }^{14} \mathrm{C}$ dating of organic deposits using natural atmospheric ${ }^{14} \mathrm{C}$ variations. Radiocarbon 31(2): 151-155.

Witte, H. J. L. and van Geel, B. 1985 Vegetational and environmental succession and net organic production between 4500 and 800 B.P. reconstructed from a peat deposit in the western Dutch coastal area (Assendelver Polder). Review of Palaeobotany and Palynology 45: 239-300.

\section{APPENDIX 1. STATISTICAL BACKGROUND}

We consider a ${ }^{14} \mathrm{C}$ sample as a population, in the statistical sense, of elements with different ${ }^{14} \mathrm{C}$ ages, $\Theta$, with the probability density function $\mathrm{P}(\Theta)$. An estimate is to be made of the "real" but unknown value, $\Theta_{\mathrm{r}}$. A laboratory measurement can be viewed as an estimate of the population mean, $\mu$. This estimate, $\hat{\mu}$, is subject to error, and thus, is not equal to the true $\mu$ value. $\hat{\mu}$ is usually taken as an estimate of $\Theta_{r}$. The total estimation error equals $\varepsilon_{t}=\left(\Theta_{r}-\hat{\mu}\right)$, and can be split into two separate errors as

$$
\varepsilon_{\mathrm{t}}=\varepsilon_{\mathrm{n}}+\varepsilon_{\mathrm{m}}=\left(\Theta_{\mathrm{r}}-\mu\right)+(\mu-\hat{\mu}) .
$$

Because $\theta_{\mathrm{r}}$ is unknown, it may be any of the $\Theta$ values in the population. Thus, $\boldsymbol{\theta}_{\mathrm{r}}$ is replaced in Equation 1.1 by the stochastic variable $\Theta$ representing all the possible ${ }^{14} \mathrm{C}$ ages in the sample. The total estimation error is made up partly of the natural $\Theta$ variation of the population (due to the presence of elements with different ${ }^{14} \mathrm{C}$ ages), and partly of the error in estimating the population mean. The latter is the measurement error of which the standard deviation, $\sigma_{m}$, is routinely given by the laboratory. If this error has zero mean (unbiased estimate of $\mu$ ), and is independent of the natural variation represented by $(\theta-\mu)$, $\varepsilon_{t}$ has the following statistics

$$
\begin{aligned}
& \mathrm{E}\left[\varepsilon_{\mathrm{t}}\right]=0 \\
& \operatorname{VAR}\left[\varepsilon_{\mathrm{t}}\right]=\sigma_{\mathrm{t}}{ }^{2}=\sigma_{\mathrm{n}}{ }^{2}+\sigma_{\mathrm{m}}{ }^{2}\left[{ }^{14} \mathrm{C} \mathrm{yr}^{2}\right]
\end{aligned}
$$

where $\quad \sigma_{n}^{2}=$ variance of $\theta$ in the sample

$$
\sigma_{\mathrm{m}}^{2}=\text { variance of the }{ }^{14} \mathrm{C} \text { measurement. }
$$

The laboratory error multiplier (Stuiver and Pearson 1986; Pearson and Stuiver 1986) is not taken into account in these formulas. If the laboratory error multiplier is considerably higher than 1.0 , it may contribute significantly to $\sigma_{t}^{2}$.

\section{APPENDIX 2. RELATION BETWEEN TIME WIDTH AND $\sigma_{\text {n }}$}

Figure 9 illustrates the relation between sample time width and natural $\Theta$ variation. Note that this relation only holds for uncontaminated samples. Total $\Theta$ variation in a sample can be attributed to two sources: 1) variation due to different ages within the sample resulting from sample time width; and 2) variation due to ${ }^{14} \mathrm{C}$ variations (wiggles)

$$
\Theta=\Theta_{\mathrm{tw}}+\varepsilon_{\mathrm{w}} .
$$

Figure 9 shows two curves. One is part of the most detailed calibration curve $\left(\sigma_{3}=8\right)$; the other is part of the $\sigma_{3}=200$ calibration curve, which can be assumed to be a straight line over such short intervals. The $\sigma_{\mathbf{s}}=200$ line represents the linear trend of the calibration curve, which can be viewed as the variation of $\Theta$ due to different ${ }^{14} \mathrm{C}$ ages within the sample. The slope $\alpha$ of the $\sigma_{2}=200$ line is determined by: 


$$
\alpha=\left(T_{\max }-T_{\min }\right) /\left(\Theta_{\max }-\theta_{\min }\right) .
$$

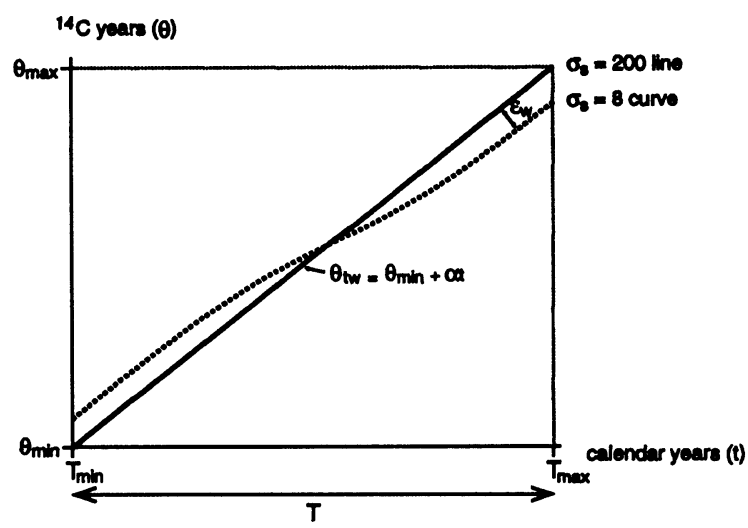

Fig. 9. Determination of parameters for the conversion of time width values to values of $\sigma_{n}$. Small parts of the high-resolution $\left(\sigma_{2}\right.$ $=8$ ) calibration curve and a strongly smoothed curve without wiggles $\left(\sigma_{3}=200\right)$ are depicted. $\alpha$ is the slope of the $\sigma_{3}=200$ line, which is assumed to be straight over such short intervals. $\sigma_{w}$ is the standard deviation of the difference between the two calibration curves.

Both $\Theta_{\mathrm{tw}}$ and $\varepsilon_{\mathrm{w}}$ are random, because the actual values are unknown. $\boldsymbol{\Theta}_{\mathrm{tw}}$ can be written as a function of time according to (see Fig. 9)

$$
\Theta_{\mathrm{tw}}(\mathrm{t})=\Theta_{\min }+\alpha \mathrm{t}
$$

where the exact but unknown calendar age, $t$, is now the random variable. Because $t$ has a uniform probability distribution within the time width $T\left(T_{\max }-T_{\min }\right)$, the mean and the variance of $\Theta_{t w}$ can be calculated easily with

$$
\begin{gathered}
\bar{\Theta}_{t w}=\Theta_{\min }+(\alpha T) / 2 \\
\left(\sigma_{\theta t w}\right)^{2}=\alpha^{2} T^{2} / 12 .
\end{gathered}
$$

Hence, the natural sample error becomes

$$
\sigma_{\mathrm{n}}(\mathrm{t}, \mathrm{T})=\sqrt{ }\left(\left(\sigma_{\Theta t w}\right)^{2}+\sigma_{w}{ }^{2}\right)=\sqrt{ }\left(\alpha^{2} \mathrm{~T}^{2} / 12+\sigma_{w}{ }^{2}\right)\left[{ }^{14} \mathrm{C} \mathrm{yr}\right] .
$$

The slope of the linear trend of the calibration curve, $\alpha$, and the standard deviation of the wiggles, $\sigma_{w}$, can be determined from the relevant part of the calibration curve.

\section{APPENDIX 3. CALCULATION OF IPbs AND Ifxp}

The observed intensity, $\mathrm{I}_{\mathrm{i}}^{\text {obs }}$, for each C-class is obtained by dividing the intensity for each C-class, $\mathrm{I}_{\mathrm{i}}^{\mathrm{c}}$, by the total intensity of the "real" ${ }^{14} \mathrm{C}$ histogram, Itot (Fig. 10A)

$$
\text { where } \quad \sum_{i=1}^{8} I_{i}^{\text {obs }}=1 \text {. }
$$

$$
\mathrm{I}_{\mathrm{i}}^{\mathrm{obs}}=\mathrm{I}_{\mathrm{i}}^{\mathrm{c}} / \mathrm{I}^{\mathrm{tot}}
$$

If the large-scale distribution of ${ }^{14} \mathrm{C}$ ages in the "real" ${ }^{14} \mathrm{C}$ histogram is homogeneous, $\mathrm{I}_{\mathrm{i}}^{\text {exp }}=0.125$. However, due to the irregular distribution of the C-classes over the ${ }^{14} \mathrm{C}$ time scale (Figs. $3 \mathrm{C}-\mathrm{E}$ ) and the unequal large-scale distribution of ${ }^{14} \mathrm{C}$ ages in the "real" ${ }^{14} \mathrm{C}$ histograms (Fig. 1), this is not the case, making it necessary to calculate a weighted expected intensity ( $\mathrm{I}_{\mathrm{i}}^{\exp }$ ) for each C-class. The ${ }^{14} \mathrm{C}$ axis of the "real" ${ }^{14} \mathrm{C}$ histograms is subdivided into 12 segments of $500{ }^{14} \mathrm{C}$ yr each $(110-600,610$ 


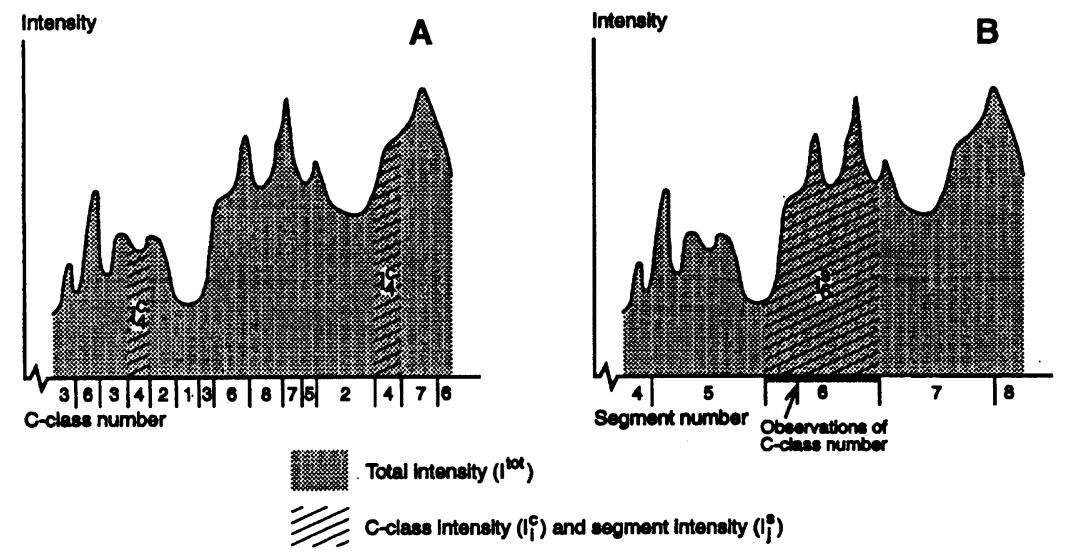

Fig. 10. Determination of total intensity, $\mathrm{I}^{\mathrm{tot}},(\mathrm{A})$ intensity of individual C-classes, $\mathrm{I}_{\mathrm{i}}^{\mathrm{c}},(\mathrm{B})$ intensity of individual segments, $I_{j}^{*}$

$1110, \ldots, 5610-6100 \mathrm{yr} \mathrm{BP}$ ), and the intensity for each segment, $I_{\mathrm{j}}^{8}$, is determined (Fig. 10B). The weight factor for each segment is

$$
\lambda_{j}=I_{j}^{s} / I^{\text {tot }}
$$

$$
\text { where } \quad \sum_{j=1}^{12} \lambda_{j}=1
$$

In each segment, the C-class number has been determined for every 10th ${ }^{14} \mathrm{C}$ yr, totaling 50 observations per segment (Fig. 10B). The number of times that $C$-class $i$ is encountered in segment $j, C_{i j}$, is determined, and the relative frequency of each C-class for each segment is obtained by

$$
\mathrm{RF}_{\mathrm{ij}}=\mathrm{C}_{\mathrm{ij}} / 50
$$

where $\quad \sum_{i=1}^{8} R F_{i j}=1$.

The expected intensity for each C-class is then calculated as

$$
I_{i}^{\exp }=\sum_{j=1}^{12}\left(\lambda_{j} \cdot R F_{i j}\right)
$$

where

$$
\sum_{i=1}^{8}\left(\sum_{j=1}^{12}\left(\lambda_{j} \cdot R F_{i j}\right)\right)=1
$$

\section{APPENDIX 4. RELATION BETWEEN $\sigma_{8}$ AND $\sigma_{t}$}

Because the smoothing parameter, $\sigma_{z}$, is expressed in cal yr and the total sample error, $\sigma_{\mathfrak{t}}$ in ${ }^{14} \mathrm{C}$ yr, their mutual relation is not straightforward. This can be problematic in cases where $\sigma_{3}$-a plots cannot be calculated (e.g., due to insufficient data), and the choice of a calibration curve is based on an estimate of $\sigma_{t} \cdot \sigma_{t}$ is a mean value for large data sets that are nearly always distributed over several millennia. Because $\sigma_{\mathbf{s}}$ is constant for the whole time scale, a correction factor, $\mathbf{Q}$, can be determined for converting $\sigma_{t}$ into $\sigma_{s}$ by

$$
\mathrm{Q}=\Delta \mathrm{cal} \mathrm{yr} / \Delta{ }^{14} \mathrm{C} \mathrm{yr} \text {. }
$$

In this equation, $\Delta{ }^{14} \mathrm{C}$ yr comprises the range of the total data set, provided that the ${ }^{14} \mathrm{C}$ ages are roughly equally distributed in time. Calibration of the upper and lower limit of the ${ }^{14} \mathrm{C}$ data range with the Groningen program (van der Plicht and Mook 1989; van der Plicht 1993), using a $\sigma_{\mathbf{3}}=200$ smoothed calibration curve yields $\Delta$ cal yr. 


\section{LIST OF SYMBOLS}

a slope of the $I_{i}^{\text {obs }} / I_{i}^{\text {exp }}$ ratio regression line

$\mathrm{C}$ parameter representing the degree of clustering of ${ }^{14} \mathrm{C}$ ages due to ${ }^{14} \mathrm{C}$ variations

$C_{i j} \quad$ number of occurrences of ith C-class in jth segment

I intensity of a ${ }^{14} \mathrm{C}$ histogram

$I_{i}^{c} \quad$ intensity of ith C-class

$\mathrm{I}_{i}^{\exp } \quad$ expected intensity of ith C-class in a ${ }^{14} \mathrm{C}$ histogram

$\mathrm{I}_{\mathrm{i}}^{\text {obs }} \quad$ observed intensity of ith $\mathrm{C}$-class in a ${ }^{14} \mathrm{C}$ histogram

$I_{j}^{s} \quad$ intensity of $j$ th segment

$I^{\text {tot }} \quad$ total intensity of a ${ }^{14} \mathrm{C}$ histogram

Q correction factor for determining the relation between $\sigma_{t}$ and $\sigma_{3}$

$R_{i j} \quad$ relative frequency of ith C-class in jth segment

$t \quad$ real age of $a{ }^{14} \mathrm{C}$ sample [cal yr]

$\mathrm{T}$ time width of a ${ }^{14} \mathrm{C}$ sample [cal yr]

$\alpha \quad$ slope of the linear trend of part of the $\sigma_{3}=200$ calibration curve

$\varepsilon_{\mathrm{m}} \quad$ measurement error

$\varepsilon_{\mathrm{n}} \quad$ natural sample error

$\varepsilon_{t} \quad$ total estimation error of the true ${ }^{14} \mathrm{C}$ age

$\varepsilon_{w} \quad$ error due to variation caused by wiggles

$\theta \quad{ }^{14} \mathrm{C}$ age of an individual element of a ${ }^{14} \mathrm{C}$ sample

$\Theta_{\mathrm{r}} \quad$ real age of a ${ }^{14} \mathrm{C}$ sample $\left[{ }^{14} \mathrm{C} \mathrm{yr}\right]$

$\Theta_{\mathrm{tw}} \quad$ variation of ${ }^{14} \mathrm{C}$ ages caused by time width $\left[{ }^{14} \mathrm{C} \mathrm{yr}\right]$

$\lambda_{j} \quad$ weight factor

$\mu \quad$ mean age of a ${ }^{14} \mathrm{C}$ sample $\left[{ }^{14} \mathrm{C} \mathrm{yr}\right]$

$\hat{\mu} \quad$ estimation of mean age of a ${ }^{14} \mathrm{C}$ sample $\left[{ }^{14} \mathrm{C} \mathrm{yr}\right.$ ]

$\sigma_{m} \quad$ standard deviation of measurement error $\left[{ }^{14} \mathrm{C} \mathrm{yr}\right]$

$\sigma_{\mathrm{n}} \quad$ standard deviation of natural sample error $\left[{ }^{14} \mathrm{C} \mathrm{yr}\right]$

$\sigma_{3} \quad$ smoothing parameter [cal yr]

$\sigma_{t} \quad$ standard deviation of total sample error $\left[{ }^{14} \mathrm{C}\right.$ yr $]$

$\sigma_{w} \quad$ standard deviation of wiggles $v s$. a regression line $\left[{ }^{14} \mathrm{C} \mathrm{yr}\right]$

$\sigma_{\Theta t w} \quad$ standard deviation of variation of ${ }^{14} \mathrm{C}$ ages caused by time width $\left[{ }^{14} \mathrm{C} \mathrm{yr}\right]$ 